УДК: 615.322:582.998.1:615.451.16:615.275.4

\title{
АНТИОКСИДАНТНАЯ АКТИВНОСТЬ ЭКСТРАКТОВ ВАСИЛЬКА ЛУГОВОГО (CENTAUREA JACEA L.) И ВАСИЛЬКА ЛОЖНОПЯТНИСТОГО (CENTAUREA PSEUDOMACULOSA DOBROCZ.)
}

\author{
(C) Т.В. Кадырова , Е.В. Ермилова, М.С. Ларькина \\ Сибирский государственный медицинский университет, Московский тр., 2, \\ Томск, 634050 (Россия), e-mail: nedel@sibmail.com
}

При исследовании антиоксидантной активности экстрактов из надземной части василька лугового (Centaurea jacea L.) и василька ложнопятнистого (Centaurea pseudomaculosa Dobrocz.) установлено, что выраженной антиоксидантной активностью обладают экстракты василька лугового, полученные с использованием 70\% этанола. Разделение активного экстракта василька лугового на фракции не приводит к увеличению антиоксидантной активности. Степень выраженности антиоксидантных свойств коррелирует с содержанием как флавоноидов, так и гидроксикоричных кислот.

Ключевые слова: Centaurea jacea L., Centaureaa pseudomaculosa Dobrocz., антиоксидантная активность.

\section{Введение}

В последнее время широкое применение находит терапия с использованием различных антиоксидантов природного происхождения, которые способны регулировать обменные процессы в организме, прерывать развитие свободно-радикальных патологий, образуя малоактивные радикалы, легко выводящиеся из организма.

Задача ускоренного поиска новых растительных антиоксидантов успешно решается с помощью вольтамперометрического метода определения суммарной антиоксидантной активности биологически активных веществ.

Среди природных антиоксидантов важное значение имеют растительные фенольные соединения, гидроксильные группы которых содержат подвижные атомы водорода, легко реагирующие с перекисными радикалами и обрывающие цепи окисления.

В качестве объектов исследования выбраны василек луговой (Centaurea jacea L.) и в. ложнопятнистый (Centaurea pseudomaculosa Dobrocz.), которые являются представителями рода Centaurea сем. Asteraceae, насчитывающего более 80 видов на территории стран СНГ.

Фенольные соединения изучаемых видов представлены флавоноидами, гидроксикоричными кислотами, кумаринами, дубильными веществами. Согласно литературным и полученным нами данным в надземной части василька лугового содержатся флавоноиды: цирсилиол, центауреидин, центауреин, яцеин, яцеозид, эупаторин, апигенин, гиспидулин, кверцетин, аксилларин, 6-метоксикемпферол 3-метиловый

Кадырова Татьяна Владимировна - доцент кафедры фармацевтической химии, кандидат фармацевтических наук, тел.: (3822) 42-64-41, e-mail: kadyrov2@sibmail.com

Ермилова Елена Васильевна - заведующая кафедрой фармацевтической химии, доктор фармацевтических наук, e-mail: nedel@sibmail.com,mmmaria@sibmail.com Ларькина Мария Сергеевна - доцент кафедры фармацевтической химии, кандидат фармацевтических наук, e-mail: mmmaria@sibmail.com эфир, изокемпферид, гидроксикоричные кислоты (ГКК): феруловая, хлорогеновая и кофейная $[1,2]$.

В васильке ложнопятнистом найдены апигенин, эупаторин, сальвигенин, витексин, виценин и ориентин, хлорогеновая и кофейная кислоты [1].

Цель работы - исследование антиоксидантной активности ряда экстрактов и фракций из надземной части василька лугового и в. ложнопятнистого.

\footnotetext{
* Автор, с которым следует вести переписку.
} 


\section{Экспериментальная часть}

Надземные части василька лугового и василька ложнопятнистого были собраны в июле 2012 г., в фазах бутонизации и цветения в окрестностях г. Томска, Томской обл. Влажность высушенного сырья определяли по методике Государственной фармакопеи СССР (1987) [3]. Экстракты получали с использованием 40, 70 и 95\% этанола методом мацерации при нагревании.

Антиоксидантную активность (АОА) полученных экстрактов и фракций определяли методом катодной вольтамперометрии, основанным на модельной реакции электровосстановления кислорода, которая протекает на электроде, по механизму, аналогичному восстановлению кислорода в тканях и клетках организма $[4,5]$.

Для оценки антиоксидантной активности снимали вольтамперограммы катодного восстановления кислорода с помощью вольтамперометрического анализатора ТА-2 («Техноаналит», Томск) на ртутнопленочном электроде в постоянно-токовом режиме при следующих условиях: скорость развертки потенциала $20 \mathrm{mB} / \mathrm{c}$, диапазон рабочих потенциалов 0-0,6 В, время перемешивания раствора 10 с, время релаксации 20 с. В качестве электрода сравнения использовали хлоридсеребряный электрод, фоновым электролитом служил 0,1 моль/л водный раствор $\mathrm{NaClO}_{4}$.

Чтобы устранить необходимость контроля содержания кислорода в растворе, перед исследованием каждого экстракта раствор перемешивали в открытой ячейке до полного насыщения фонового раствора кислородом воздуха, что обусловливало неизменность концентрации кислорода, равной его растворимости в данном растворителе при нормальных условиях, при переходе от раствора к раствору [4].

Для получения значения предельного тока электровостановления $\mathrm{O}_{2}$ в отсутствие вещества в растворе $\left(I_{\text {нач}}\right)$ регистрацию катодной вольтамперограммы тока электровосстановления $\mathrm{O}_{2}$ повторяли 5 раз.

Количественное определение флавоноидов проводили методом дифференциальной спектрофотометрии с использованием комплексообразующей реакции с алюминия хлоридом. В качестве стандарта приняли образец апигенина (Sigma).

Для количественного определения гидроксикоричных кислот использовали метод экстракционной спектрофотометрии, позволяющий определять сумму ГКК в присутствии флавоноидов [6, 7].

\section{Обсуждение результатов}

Экспериментальные данные (табл. 1,2) показали, что все полученные экстракты из надземных частей василька лугового и в. ложнопятнистого проявляют антиоксидантные свойства по отношению к процессу электровосстановления кислорода. Однако наиболее выражена АОА экстрактов василька лугового, причем экстракт, полученный на 70\% этаноле, обладает наиболее высокой АОА, которая сравнима с активностью дигидрокверцетина и немного ниже, чем у аскорбиновой кислоты.

Для выявления природы БАВ, ответственных за АОА, проведено фракционирование экстракта василька лугового, полученного с использованием 70\% этанола, рядом растворителей с увеличивающейся полярностью: хлороформом, этилацетатом, бутанолом.

Для полученных фракций изучена АОА. Экспериментальные данные (табл. 3) свидетельствуют, что наибольшей антиоксидантной активностью обладает этилацетатная фракция, кинетический критерий которой близок к АОА экстракта василька лугового, полученного с использованием 70\% этанола. Несколько более низкое значение АОА имеет бутанольная фракция.

Таблица 1. Антиоксидантная активность экстрактов Centaurea jacea L.

\begin{tabular}{c|c|c|c|c|c}
\hline $\begin{array}{c}\text { Рабочая концентрация, } \\
\text { С г/мл }\end{array}$ & Наименование образца & $\overline{\mathrm{K}}$ & $S^{2}$ & $S$ & $\Delta \overline{\mathrm{K}}$ \\
\hline \multirow{2}{*}{0,0005} & Экстракт на 40\% этаноле & 0,32 & 0,00063 & 0,025 & 0,06 \\
& Экстракт на 70\% этаноле & 1,14 & 0,0041 & 0,064 & 0,10 \\
& Экстракт на 95\% этаноле & 0,56 & 0,00058 & 0,024 & 0,06 \\
\hline 0,0005 & Аскорбиновая кислота & 1,38 & & & 0,06 \\
\multirow{2}{*}{0,0001} & Экстракт на 40\% этаноле & 0,32 & 0,00058 & 0,024 & 0,08 \\
& Экстракт на 70\% этаноле & 0,81 & 0,0018 & 0,043 & 0,07 \\
\hline 0,0001 & Экстакт на 95\% этаноле & 0,46 & 0,0019 & 0,044 & \\
\hline 0,0001 & Дигидрокверцетин & 0,78 & & & \\
\hline
\end{tabular}


Таблица 2. Антиоксидантная активность экстрактов Centaurea pseudomaculosa Dobrocz.

\begin{tabular}{c|c|c|c|c|c}
\hline $\begin{array}{c}\text { Рабочая концентрация, } \\
\text { С г/мл }\end{array}$ & Наименование образца & $\overline{\mathrm{K}}$ & $S^{2}$ & $S$ & $\Delta \overline{\mathrm{K}}$ \\
\hline \multirow{2}{*}{0,001} & Экстракт на 40\% этаноле & 0,18 & 0,000100 & 0,010 & 0,02 \\
& Экстракт на 70\% этаноле & 0,61 & 0,000196 & 0,014 & 0,03 \\
& Экстракт на 95\% этаноле & 0,28 & 0,000025 & 0,0050 & 0,01 \\
\hline \multirow{2}{*}{0,0001} & Экстракт на 40\% этаноле & 0,12 & 0,000041 & 0,0064 & 0,02 \\
& Экстракт на 70\% этаноле & 0,51 & 0,000442 & 0,021 & 0,09 \\
& Экстракт на 95\% этаноле & 0,20 & 0,000083 & 0,0091 & 0,02 \\
\hline 0,0001 & Дигидрокверцетин & 0,78 & & & \\
\hline
\end{tabular}

Таблица 3. Антиоксидантная активность фракций 70\% этанольного экстракта Centaurea jacea L.

\begin{tabular}{c|c|c|c|c|cc}
\hline Рабочая концентрация, С г/мл & Наименование образца & $\overline{\mathrm{K}}$ & $S^{2}$ & $S$ & $\Delta \overline{\mathrm{K}}$ \\
\hline \multirow{3}{*}{0,0001} & Хлороформная & 0,23 & 0,000121 & 0,011 & 0,02 \\
& Этилацетатная & 0,72 & 0,00008 & 0,009 & 0,02 \\
& Бутанольная & 0,49 & 0,0001 & 0,012 & 0,03 & 0,08 \\
\hline \multirow{3}{*}{0,0005} & Экстракт на 70\% этано- & 0,81 & 0,0018 & 0,043 & 0,083 & 0,06 \\
& ле & 0,82 & 0,007 & 0,0004 & 0,05 \\
& Хлороформная & 1,15 & 0,0019 & 0,07 \\
& Этилацетатная & 1,08 & 0,019 & 0,101 & 0,10 \\
\hline
\end{tabular}

Как известно, АОА экстрактов связывают с содержанием полифенольных соединений. Поэтому нами проведена оценка количественного содержания некоторых групп БАВ, обладающих антиоксидантными свойствами, в частности флавоноидов и гидроксикоричных кислот.

Содержание флавоноидов (табл. 4) в экстрактах василька лугового, полученного с использованием 70 и 95\% этанола, отличается незначительно и составляет 4,44\% $\pm 0,07$ и 4,17\% $\pm 0,12 \%$ соответственно.

Результаты количественного определения гидроксикоричных кислот в надземной части василька лугового свидетельствуют о наибольшем содержании их в экстрактах, полученных с использованием 70 и $95 \%$ этанола $(2,23 \pm 0,07 \%$ и $1,83 \pm 0,03 \%$ соответственно).

Количественное содержание флавоноидов и гидроксикоричных кислот в надземной части василька ложнопятнистого значительно ниже, чем в надземной части василька лугового.

Таблица 4. Результаты количественного определения флавоноидов и гидроксикоричных кислот в надземных частях василька лугового и василька ложнопятнистого (экстрагент - этанол)

\begin{tabular}{|c|c|c|c|c|c|c|}
\hline \multirow{3}{*}{ Вид } & \multicolumn{3}{|c|}{ Флавоноиды } & \multicolumn{3}{|c|}{ Гидроксикоричные кислоты } \\
\hline & \multicolumn{6}{|c|}{ Концентрация этанола, \% } \\
\hline & 95 & 70 & 40 & 95 & 70 & 40 \\
\hline Василек луговой & $4,17 \pm 0,12$ & $4,44 \pm 0,07$ & $3,36 \pm 0,08$ & $1,83 \pm 0,03$ & $2,23 \pm 0,07$ & $1,36 \pm 0,02$ \\
\hline Василек ложнопятнистый & $0,48 \pm 0,02$ & $0,93 \pm 0,02$ & $0,91 \pm 0,02$ & $0,33 \pm 0,02$ & $0,45 \pm 0,01$ & $0,25 \pm 0,03$ \\
\hline
\end{tabular}

\section{Выводы}

1. Установлено, что экстракты, полученные на 95, 70 и 40\% этаноле из надземных частей василька лугового (Centaurea jacea L.) и василька ложнопятнистого (Centaurea pseudomaculosa Dobrocz.), обладают антиоксидантной активностью, однако наиболее выражена она у экстрактов василька лугового.

2. Выявлено, что экстракт василька лугового, полученный с использованием 70\% этанола, обладает наибольшей антиоксидантной активностью (по кинетическому критерию), сравнимой с АОА дигидрокверцетина (при концентрации 0,0001 г/мл).

3. Разделение активного экстракта на фракции нецелесообразно, так как не приводит к увеличению антиоксидантной активности. 
4. Полученные данные о количественном содержании флавоноидов и гидроксикоричных кислот в исследуемых экстрактах василька лугового свидетельствуют о том, что степень выраженности антиоксидантных свойств коррелирует с содержанием как флавоноидов, так и гидроксикоричных кислот.

\section{Список литературы}

1. Ларькина М.С., Кадырова Т.В., Ермилова Е.В. Фенольные соединения видов рода Сеntaurea мировой флоры (обзор) // Химия растительного сырья. 2011. №4. С. 7-14.

2. Forgo P., Zupkó I., Molnár J., Vasas A., Dombi G., Hohmann J. Bioactivity-guided isolation of antiproliferative compounds from Centaurea jacea L. // Fitoterapia. 2012. Vol. 83, N5. Pp. 921-925.

3. Государственная фармакопея СССР. ХІ изд. Вып. 2: Общие методы анализа. Лекарственное сырье. М., 1990.

4. Короткова Е.И. Вольтамперометрический способ определения активности антиоксидантов // Журнал физической химии. 2000. Т. 74, №9. С. 1704-1706.

5. Короткова Е.И., Карбаинов Ю.А., Аврамчик О.А. Вольтамперометрическое определение антиоксидантной активности растительного сырья и некоторых продуктов питания // Известия вузов. Химия и химическая технология. 2002. Т. 45, №3. С. 110-112.

6. Косман В.М. Количественное экстрационно-спектрофотометрическое определение суммарного содержания гидроксикоричных кислот в присутствии флавоноидов в экстрактивных веществах некоторых лекарственных растений // Растительные ресурсы. 2001. №4. С. 123-129.

7. Кадырова Т.В., Ларькина М.С., Ермилова Е.В., Краснов Е.А., Аврамчик О.А. Антиоксидантная активность эксрактов из надземной части Centaurea scabiosa (Asteraceae) // Растительные ресурсы. 2010. Т. 46, вып. 1. C. $101-106$.

Поступило в редакциию 21 июня 2013 г.

Kadyrova T.V., Ermilova E.V., Larkina M.S. ANTIOXIDANT ACTIVITY OF THE EXTRACTS FROM CENTAUREA JACEA L. AND CENTAUREA A PSEUDOMACULOSA DOBROCZ.

Siberian State Medical University, Moskovskii trakt, 2, Tomsk, 634050 (Russia),e-mail: nedel@sibmail.com

As a result of investigation of antioxidant activity of the extracts from the aerial part of Centaurea jacea L. and Centaurea a pseudomaculosa Dobrocz.was established the evident antioxidant activity of the extract Centaurea jacea L. obtained with the use of $70 \%$ ethanol. Division of active extract into the fractions is not rational as this is not lead to increasing of antioxidant activity. Degree of the evidence of antioxidant properties is correlating with as flavonoids, as hydroxycinnamic acids content.

Keywords: Centaurea jacea L., Centaureaa pseudomaculosa Dobrocz., antioxidant activity.

\section{References}

1. Lar'kina M.S., Kadyrova T.V., Ermilova E.V. Khimiia rastitel'nogo syr'ia, 2011, no. 4, pp. 7-14. (in Russ.).

2. Forgo P., Zupkó I., Molnár J., Vasas A., Dombi G., Hohmann J. Fitoterapia, 2012, vol. 83, no. 5, pp. 921-925.

3. Gosudarstvennaia farmakopeia SSSR. XI izd.Vyp. 2: Obshchie metody analiza. Lekarstvennoe syr'e. [State Pharmacopoeia of the USSR. XI ed. Part 2: General methods of analysis. Medicinal herbs.]. Moscow, 1990. (in Russ.).

4. Korotkova E.I. Zhurnal fizicheskoi khimii, 2000, vol. 74, no. 9, pp. 1704-1706. (in Russ.).

5. Korotkova E.I., Karbainov Iu.A., Avramchik O.A. Izvestiia vuzov. Khimiia i khimicheskaia tekhnologiia, 2002, vol. 45, no. 3, pp. 110-112. (in Russ.).

6. Kosman V.M. Rastitel'nye resursy, 2001, no. 4, pp. 123-129. (in Russ.).

7. Kadyrova T.V., Lar'kina M.S., Ermilova E.V., Krasnov E.A., Avramchik O.A. Rastitel'nye resursy, 2010, vol. 46, no. 1, pp. 101-106. (in Russ.).

\footnotetext{
${ }^{*}$ Corresponding author.
} 